\title{
MATERNAL DEATH DUE TO HEALTH CARE ASSOCIATED MITRAL VALVE ENDOCARDITIS
}

\author{
Perera W.N.S.' \& Gangahawatte S.D.S. ${ }^{2}$ \\ ${ }^{1}$ Department of Forensic Medicine, Faculty of Medicine, University of Kelaniya, Sri Lanka \\ ${ }^{2}$ Office of the Judicial Medical Officer, North Colombo Teaching Hospital, Ragama, \\ Sri Lanka
}

Corresponding author: Perera W.N.S.

\begin{abstract}
Infective endocarditis in pregnancy is a rare disease accounting for $0.006 \%$ of incidents. Among the associated factors health care associated fatal infections are rarer. In this case a pregnant mother with 13 weeks of gestation was subjected to the autopsy with the history of fever following inward treatment for hyperemesis, which was the result of septic thrombophlebitis at cannula site. Suggested clinical diagnosis of bacterial endocarditis was confirmed macroscopically and microscopically during autopsy. Damage to the mitral valve, micro abscess formation, multiple thrombi formation and infractions in the organs, together with features of heart failure was evident as complications of bacterial endocarditis. This rare case highlights that the need of early diagnosis of bacterial endocarditis when a pregnant mother presents with fever and necessity of adherence to the infection control standard in clinical setting to prevent mortality and morbidity.
\end{abstract}

Keywords: Bacterial endocarditis, Cross infection, Pregnancy

All articles in Sri Lanka Journal of Forensic Medicine, Science \& Law are licensed under the terms of the Creative Commons Attribution-Non Commercial 4.0 International License. 


\section{INTRODUCTION}

Indirect causes are leading maternal deaths, with heart disease being the most common. ${ }^{1,2,3}$ Sri Lanka has a maternal mortality ratio of 33.7 per 100,000 live births, which is the lowest rate in South Asia. $^{4}$ Even though among the causes of death in pregnancy, incidents of infective endocarditis are rare as $0.006 \%, 5,6,7$ maternal mortality rate as well as fetal mortality rate is significantly high as $22.1 \%$ and $14.7 \%$ respectively. ${ }^{8}$ The diagnosis and treatment methods of infective endocarditis has improved significantly during the past few decades but mortality rate has not largely changed. ${ }^{9,10,11}$ During the pregnancy, a physician faces management difficulties in infective endocarditis due to resistance to treatment and complications leading to fatal outcome, especially in health care associated infections. ${ }^{12}$ In Sri Lanka all the maternal deaths are reviewed at institutional level as well as at national level with the participation of a management team and a forensic pathologist. Therefore, better understanding of sequelae of the disease is crucial in prevention of maternal deaths.

In this paper we present a case of fatal bacterial endocarditis at 13 weeks of gestation.

\section{CASE HISTORY}

An apparently well 29-year-old primigravida with 11 weeks of gestation presented to a base hospital with a history of hyperemesis and was treated as an inward patient. She developed septic thrombophlebitis at the cannula site while in the ward and was treated with intravenous antibiotics for one day and was discharged with oral antibiotics. Three days later she developed fever, for which treatment was taken from a General Practitioner. Within the next 2 days she was seen by the Obstetrician, who referred her to a Physician due to fever with low blood pressure and gradually worsening shortness of breath. She was treated inward for 3 days and discharged from the hospital. On the same day, her fever got worse associated with severe head ache, cough and breathlessness. The next morning, she was seen by the Obstetrician and advised to immediately admit. She got admitted to a private hospital and following several investigations, including a positive Echocardiogram for mitral value vegetations, she was transferred to an Intensive Care Unit (ICU) of a tertiary care hospital with the history of intermittent fever for 8 days' duration, blood pressure $70 / 40 \mathrm{mmHg}$ and pulse rate of 140 beats/min.

While she was in the ICU, she had fever $\left(102{ }^{0} \mathrm{~F}\right)$ with chills, investigations showed leukocytosis with Neutrophilia $(26,000$ $\mathrm{mm}^{3}, 91 \%$ ), elevated $\mathrm{C}$ reactive proteins $(389 \mathrm{mg} / \mathrm{l})$ and $\mathrm{D}$ dimer $7.2 \mathrm{mg} / \mathrm{dl}$. Blood culture was positive for gram positive cocci (Staphylococcus aureus) and repeated 2D Echocardiography confirmed vegetations on the mitral valve. Patient was treated with the antibiotics Meropenem, Vancomycin and Teicoplanin and anti-viral Tamiflu. In spite of treatment her condition deteriorated and died on the $10^{\text {th }}$ day after the fever.

There was no history of previous heart disease, foreign material implant or infections such as urinary tract infection or caries in teeth.

Autopsy examination revealed multiple petechial haemorrhages and purpura on the body. A healing scar was seen on the previously infected cannula site. Internal examination revealed a pale, oedematous brain with areas of infarction. Intracranial haemorrhages were not present. Heart was flabby and weighed 382g. Epicardium had petechial haemorrhages. Mitral valve was thickened, and $6 \mathrm{~cm}$ in length. Valve cusps had multiple vegetations, the largest being pedunculated, firm and non-calcified 
measuring $1.6 \mathrm{~cm}$ in diameter. Others were friable and smaller (Fig: 1). Chordae tendinae were thickened and shortened. Tricuspid valve and chordae tendineae showed hyperaemia (Fig: 2). There was bilateral pleural effusion measuring $100 \mathrm{ml}$ on each side with pulmonary oedema. Kidneys were swollen with wedge shaped infarctions. Spleen was enlarged. Dead fetus was found in the uterus.

Histology from the mitral valve showed bacterial vegetation over the valvular endocardium (Fig: 3) composed of neutrophils, necrotic debris and infected colonies of gram positive cocci. Inflamed granulation tissue was covered with fibrin and capillarization of valve was noted underneath the vegetation. Multiple thrombi were present. Valvular fibrosis and basophilic calcium salt deposits were not seen. Sections of the aortic, pulmonary and tricuspid valves were devoid of any structural abnormalities. Microscopy of myocardium showed distorted architecture with scattered areas of focal myocytolysis associated with neutrophil aggregation and few bacterial colonies, suggestive of developing abscesses (Fig: 4). This appearance (early abscess formation) was noted in the brain, lungs and kidneys as well (Fig: 5, 6). Areas of brain infarctions and renal infarctions were noted with thrombosis. With these observations pathological diagnosis of bacterial endocarditis was made. This overall appearance is suggestive of 10-14 days of time period since the initiation of the said pathological process. Features of the thrombophlebitis are more in favor of acute in origin $(<2$ weeks $)$.

Following autopsy cause of death was given as complications of bacterial endocarditis following septic thrombophlebitis. The questions of medical negligences arises in this case whether the due standard of care was given to the patient.

\section{DISCUSSION}

Infective endocarditis is an infection of the endocardial surface of the heart which involves heart valves or cardiac chambers. Mostly it is caused by gram positive cocci such as Streptococcus or Staphylococcus amounting to $80 \%$ of cases. ${ }^{11,13}$ Congenital heart diseases, Rheumatic valvular disease, intra-cardiac implants, intravenous drug abuse, periodontal disease and local infection are some of the risk factors. ${ }^{14,15}$ A French study stated $47 \%$ of patients having endocarditis without previous knowledge of cardiac disease similar to this case. ${ }^{9}$ It is also likely to have bacteraemia originated from nosocomial or iatrogenic infection even few months after hospital admission depending on the type of causative agent and its' virulence. ${ }^{16}$ In this case intra venous therapy which led to the septic thrombophlebitis while in the hospital is the most likely cause.

In bacterial endocarditis pathophysiology starts even as a result of micro ulceration on the valvular endothelium producing small clot or coagulum. In this patient bacteraemia is possibly associated with septic thrombophlebitis. Circulating bacteria in the blood stream bind to the coagulum and activate monocytes resulting in progressive enlargement of vegetation and further adherence of bacteria. Vegetations are composed of fibrin, platelets, and infecting organisms. This is held together by antibodies produced by bacteria. Continuing inflammation leads to erosions, ulcerations and perforation of valve cusps. ${ }^{17}$ Vegetations are mostly located in left cardiac chambers $(84.7 \%)$ predominantly on native mitral value. ${ }^{18}$ Larger vegetations lead to functional obstruction to the blood flow into the left ventricle and mitral regurgitation further reduces the ventricular filling causing pulmonary oedema and heart failure. ${ }^{19}$ Large vegetations such as $>10 \mathrm{~mm}$ is significantly associated with embolic events. $^{20}$ Presence of perivalvular 
abscesses indicate poor prognosis. ${ }^{21}$ Myocardial abscesses, inflammation and necrosis of myocardial tissue affects nerve conduction of the heart causing arrhythmia and reducing ventricular contraction. It is evident from the studies that significant number of patients show multiple complications. ${ }^{22,23}$

Clinical features as well as investigations help in diagnosis of infective endocarditis using the modified Duke criteria. $^{24}$ Among the investigations blood cultures are the standard test to conclude the etiology since this is an endovascular infection associated with persistent bacteraemia. Presence of elevated CRP and D dimer, increased leukocyte count, vegetation size of $>10 \mathrm{~mm}$, perivalvular abscesses are significantly associated with high mortality rate of bacterial endocarditis like in this case. ${ }^{25}$ Staphylococcal origin ${ }^{26}$ and health care associated native valve bacterial endocarditis are some of the other factors associated with high mortality. ${ }^{27,28}$ Hospital acquired Staphylococcus aureus infection with newly onset endocarditis is seen in studies by various proportions ranging from $5 \%-17 \% .{ }^{29,30}$

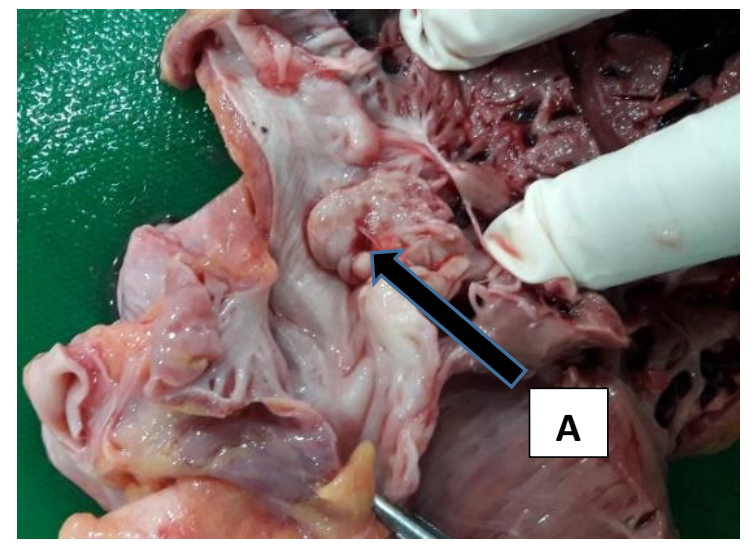

Fig 1: Photographs of the heart showing mitral valve and vegetation indicated by an arrow A
Fatal outcome of endocarditis is mostly related to complications such as valvular regurgitation, myocardial abscess formation and tissue destruction, heart failure and embolic metastasos. ${ }^{22}$ In this case heart, brain, lung and kidney tissues showed micro abscesses. Pulmonary oedema is evident as a feature of heart failure.

In this patient bacteraemia following septic thrombophlebitis led to the bacterial endocarditis and destruction of the infected mitral value causing valvular dysfunction, leading to the acute heart failure and a fatal outcome. Abscess formation and infarctions in other organs further contributed to the death. However, with the myocytolysis conduction abnormalities and fatal arrhythmias cannot be excluded in the mechanism of death.

Valvular surgery as a treatment option is limited in this case due to multisystem involvement with rapid deterioration of the patient and scarcity of available resources for surgery.

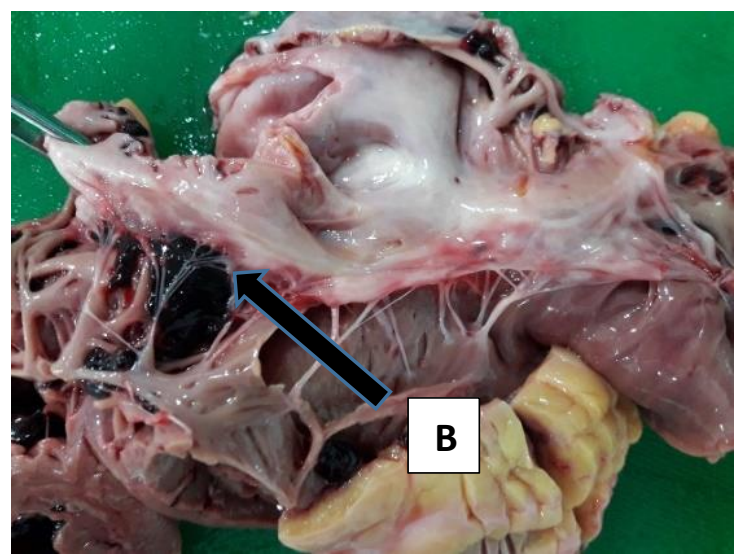

Fig 2: Photographs of the heart showing hyperaemia around the tricuspid valve indicated by an arrow B 


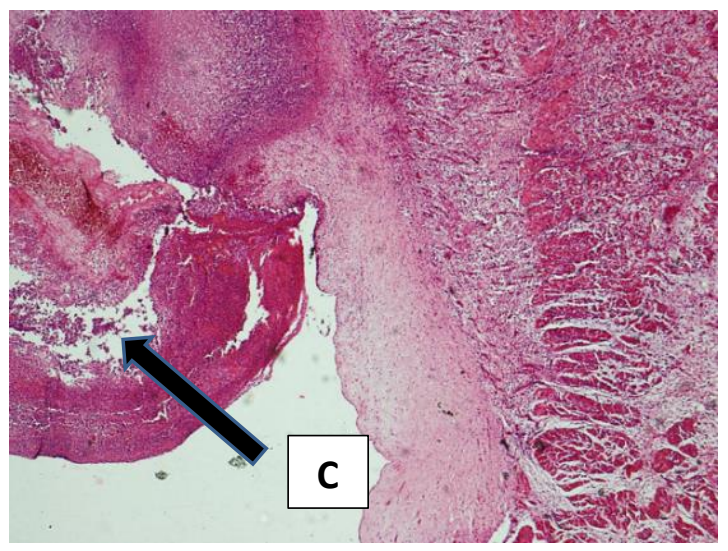

Fig 3: Microphotograph of the heart (H\&E 4x10) showing vegetation on the mitral valve indicated by an arrow $C$

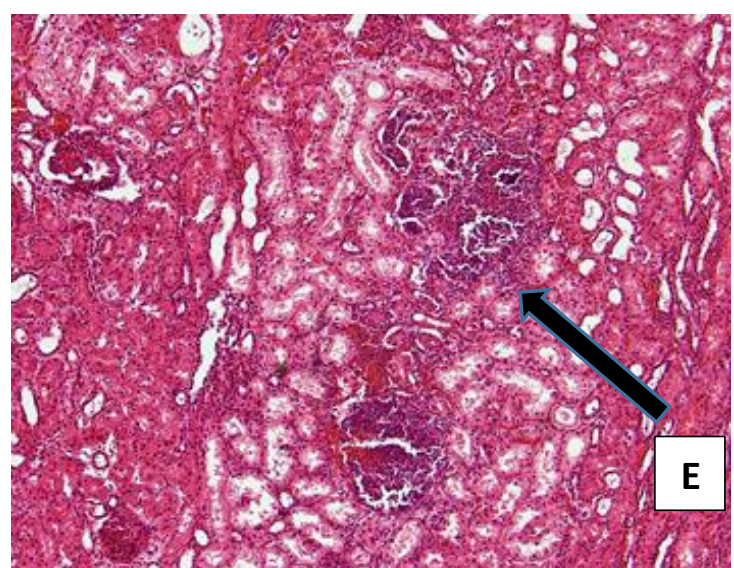

Fig 5: Microphotograph of the kidney showing (H \& E 40x10) micro abscess indicated by an arrow $E$

\section{CONCLUSION}

This case illustrates rare presentation of acute ulcerative polypoid endocarditis on a native valve with disseminated abscess formation due to septic embolization in a pregnant mother with 13 weeks of gestation. Special attention is needed to suspect bacterial endocarditis when pregnant mothers are presented with fever in a clinical setting. Early diagnosis of endocarditis based on modified Dukes criteria and identification of the most effective treatment is mandatory in

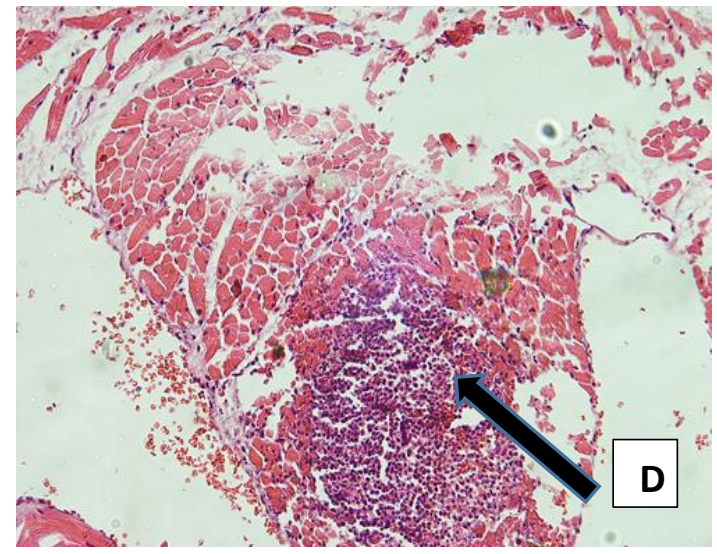

Fig 4: Microphotograph of the heart showing (Gram staining 4x10) micro abscess indicated by an arrow $D$

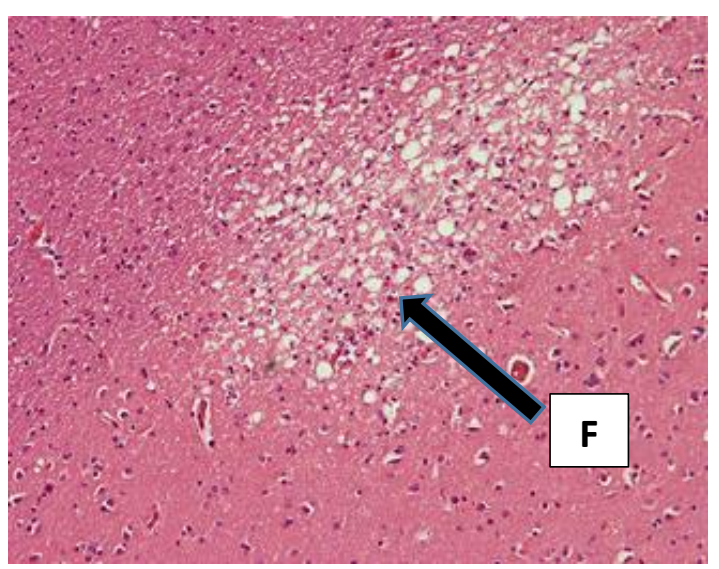

Fig 6: Microphotograph of the brain showing (H \& E 4x10) micro abscess indicated by an arrow $F$

reducing the complications and risk of fetal and maternal mortality. Infection control standard precautions in health care should be applied strictly in the ward setting to prevent health care associated infections.

\section{ACKNOWLEDGEMENT}

Dr. Pradeep Bandara (Consultant JMO) for histopathology reporting. 
1. Say L, Chou D, Gemmill A, Tunçalp Ö, Moller AB, Daniels JD, et al. Global Causes of Maternal Death: A WHO Systematic Analysis. Lancet Global Health. 2014;2(6): e323-e333.

2. Umadethan B. Principal and practical of forensic medicine. 2nd ed. New Delhi: CBS Publishers and Distributers pvt;2016. p. 289.

3. A.Vadysinghe, R.Jayasooriya, G. K. Gunatilake \& M. Sivasubramanium, Unexpected sudden death in pregnancy arrhythmogenic right ventricular cardiomyopathy/dysplasia: a case report, Forensic Sciences Research, 2:3, 161-163, DOI: 10.1080/20961790. 2017.1325548.

4. D.Weerasekara, Presidential address, April 2017, Sri Lanka Journal of Obstetrics and Gynaecology, www.slcog.lk/sljog.

5. Cox SM, Hankins GD, Leveno KJ, Cunningham FG. Bacterial endocarditis. A serious pregnancy complication. J Reprod Med 1988; 33: 671-4.

6. Ward H, Hickman RC. Bacterial endocarditis in pregnancy. Aust.NZJ Obstet. Gynaecol. 1971;11:189-191.

7. Nazarian M, McCullough GH, Fielder DL. Bacterial endocarditis in pregnancy: successful surgical correction. J Thorac Cardiovasc Surg. 1976;71:880-883.

8. Campuzano $\mathrm{K}$, Roquè $\mathrm{H}$, Bolnick $\mathrm{A}$, Leo MV, Campbell WA. Bacterial endocarditis complicating pregnancy: case report and systemic review of the literature. Arch Gynecol Obstet 2003; 268: 251-5.

9. Hoen B, Alla F, Selton-Suty C, et al. Changing profile of infective endocarditis. Results of a 1-year survey in France. JAMA. 2002;288(1):75-81.

10. Cabell CH, Jollis JG, Peterson GE, et al. Changing patient characteristics and the effect on mortality in endocarditis. Arch Intern Med. 2002;162(1):90-94.
11. Rhys P Beynon, V.K.Bahl,Bernard D Prendergast, Infective Endocarditis, BMJ. 2006 Aug 12; 333(7563): 334-339.

12. Mocchegiani $R, \quad$ Nataloni $M$. Complications of infective endocarditis. Cardiovasc Hematol Disord Drug Targets 2009; 9:240-8.

13. Liesman RM, Pritt BS, Maleszewski JJ, Patel R. 2017. Laboratory diagnosis of infective endocarditis. J Clin Microbiol 55:2599-2608.

14. Ambrosioni J, Hernandez-Meneses M, Téllez A, et al. The Changing Epidemiology of Infective Endocarditis in the Twenty-First Century. Curr Infect Dis Rep 2017; 19:21.

15. Erbay AR, Erbay A, Canga A, et al. Risk factors for in-hospital mortality in infective endocarditis: five years' experience at a tertiary care hospital in Turkey. J Heart Valve Dis 2010; 19:216.

16. Bouza E, Menasalvas A, Munoz P, Vasallo FJ, del Mar Moreno M, Garcia Fernandez MA. Infective endocarditis - a prospective study at the end of the twentieth century: new predisposing conditions, new etiologic agents, and still a high mortality. Medicine (Baltimore) 2001;80: 298-307.

17. Thiene G, Basso C, Pathology and pathogenesis of infective endocarditis in native heart valves. Cardiovasc Pathol. 2006 Sep-Oct ;15(5): 256-263. doi: 10.1016/j.carpath. 2006.05.009.

18. Marina Leitman, Yael Dreznik, Vladimir Tyomkin, Therese Fuchs, Ricardo Krakover, Zvi Vered, Vegetation size in patients with infective endocarditis, European Journal of Echocardiography, Volume 13, Issue 4, April 2012, 330-338.

19. Michael A. Hart, Infective endocarditis causing mitral valve stenosis - a rare but deadly complication: a case report, J Med Case Rep. 2017; 11: 44. 
20. Kelechi E. Okontaa,Yahaya B. Addamu, What size of vegetation is an indication for surgery in endocarditis?. Interact Cardiovasc Thorac Surg. 2012 Dec; 15(6): 1052-1056., Published online 2012 Sep 7.

21. Mugge A, Daniel WG. Echocardiographic assessment of vegetations in patients with infective endocarditis: prognostic implications. Echocardiography. 1995;12:651-61.

22. Timothy E. Paterick, Rick A. Nishimura, James M. Steckelberg, Complexity and Subtlety of Infective Endocarditis, Mayo clinic proceedings, May 2007,Volume 82, Issue 5, Pages 615-621.

23. Gilleece A, Fenelon L, Nosocomial infective endocarditis, J Hosp Infect. 2000 Oct; 46(2):83-8.

24. Durack DT, Lukes AS, Bright DK, New criteria for diagnosis of infective endocarditis: utilization of specific echocardiographic findings, Am J Med. 1994 Mar; 96(3):200-9.

25. Demirbag R, Using the D- dimer test in infective endocarditis, Turk Kardiyol Dern Ars. 2013 Oct;41(7):595-7. doi: 10.5543/tkda.2013.09483.

26. V. Kremery, et el, Etiology and Risk Factors of 339 Cases of Infective Endocarditis: Report from a 10-year National Prospective Survey in the Slovak Republic, Journal of Chemotherapy, Volume 15, 2003 - Issue 6.
27. Hill EE, Herijgers $P$, Claus $P$, Vanderschueren S, Herregods MC, Peetermans WE. Infective endocarditis: changing epidemiology and predictors of 6month mortality: a prospective cohort study. Eur Heart J. 2007;28:196-203.

28. Hasbun R1, Vikram HR, Barakat LA, Buenconsejo J, Quagliarello VJ. Complicated left-sided native valve endocarditis in adults: risk classification for mortality, JAMA. 2003 Apr 16;289(15):1933-40.

29. Chang, Feng-Yee; MacDonald, Brent B.; Peacock, James E. Jr; Musher et al, A Prospective Multicenter Study of Staphylococcus Aureus Bacteremia: Incidence of Endocarditis, Risk Factors for Mortality, and Clinical Impact of Methicillin Resistance, Medicine: September 2003 - Volume 82 - Issue 5 - p 322-332.

30. Ronen Ben-Ami, Michael Giladi, Yehuda Carmeli, Ruth Orni-Wasserlauf, Yardena Siegman-Igra, Hospital-Acquired Infective Endocarditis: Should the Definition be Broadened? Clinical Infectious Diseases, Volume 38, Issue 6, 15 March 2004, Pages 843-850, https://doi.org/10.1086/381971 